Artigo

\title{
IMPLEMENTAÇÃO DA DISCIPLINA DE LIBRAS NOS ANOS INICIAIS: UMA PERSPECTIVA BILÍNGUE
}

\author{
IMPLEMENTATION OF POLE DISCIPLINE IN THE EARLY YEARS: A BILINGUAL \\ PERSPECTIVE
}

\author{
IMPLEMENTACIÓN DE LA DISCIPLINA DE LAS LIBRAS EN LOS PRIMEROS \\ AÑOS: UNA PERSPECTIVA BILINGÜE
}

\author{
Yuri Miguel Macedo \\ Albery Pires França Vasconcelos \\ Crizeide Miranda Freire \\ Juciara Costa da Fonseca Rios
}

\begin{abstract}
Resumo
A efetivação do exercício da proposta da Educação Bilíngue, a partir de políticas públicas, possibilita aos surdos o aprendizado priorizando a língua de sinais como língua de instrução. Esta perspectiva perpassa a visão conteudista, ela abre caminhos para interação, socialização entre surdos e ouvintes e a difusão da língua de sinais para além dos muros da escola. Assim, nesta linha de entendimento, este artigo foi orientado pela seguinte questão central: a implementação da disciplina Libras nas séries iniciais do ensino fundamental I, contribuiria na formação do sujeito surdo e na promoção efetiva de inclusão entre surdos e ouvintes? Para tanto, os objetivos traçados foram: Compreender o bilinguismo como caminhos para efetivação da inclusão, tendo em vista a implementação da disciplina de Libras nos anos iniciais, elencando ações para que essas políticas sejam executadas analisar de que maneira, ter a sua língua materna no início de sua formação favoreceria no processo identitário do sujeito surdo; Investigar as políticas públicas e as legislações educacionais, como subsídios que possibilitarão a implementação da disciplina de Libras nos anos iniciais na perspectiva de uma escola bilíngue e perceber como os integrantes das escolas concebem a implantação da disciplina de libras nas séries iniciais enquanto promoção da inclusão de surdos. Percorremos os caminhos metodológicos a partir da abordagem qualitativa, com inspiração no estudo de caso, alicerçada por instrumentos como visitas de campo, entrevista semiestruturada e observação. Os sujeitos da pesquisa foram alunos surdos, ouvintes, intérprete e também professores que corroboraram em suas falas a importância da implementação da disciplina Libras para surdos e ouvintes a partir das séries iniciais do fundamental I, uma vez que, dentre outras coisas favorecerá no processo identitário e de comunicação.
\end{abstract}

\footnotetext{
Abstract

The realization of the exercise of the Bilingual Education proposal, based on public policies, enables deaf people to learn by prioritizing sign language as the language of instruction. This perspective permeates the content view, it opens paths for interaction, socialization between deaf and listeners and the diffusion of sign language beyond the walls of the school. Thus, in this line of understanding, this article was guided by the following central question: would the implementation of the Libras discipline in the initial grades of elementary school I, contribute to the formation of the deaf subject and the effective promotion of inclusion among deaf and hearing people? To this end, the
} 
objectives outlined were: To understand bilingualism as ways to make inclusion effective, with a view to implementing the Libras discipline in the early years, listing actions for these policies to be carried out, analyzing how, having their mother tongue in the beginning of his training would favor the deaf subject's identity process; Investigate public policies and educational legislation, as subsidies that will enable the implementation of the Libras discipline in the early years from the perspective of a bilingual school and understand how school members conceive the implementation of the Libras discipline in the initial grades while promoting the inclusion of deaf. We followed the methodological paths based on the qualitative approach, inspired by the case study, based on instruments such as field visits, semi-structured interviews and observation. The research subjects were deaf students, listeners, interpreter and also teachers who corroborated in their speeches the importance of implementing the Libras discipline for the deaf and listeners from the initial grades of elementary I, since, among other things, it will favor the identity process and communication.

\section{Resumen}

La realización del ejercicio de la propuesta de Educación Bilingüe, basada en políticas públicas, permite que las personas sordas aprendan priorizando el lenguaje de señas como el idioma de instrucción. Esta perspectiva impregna la vista del contenido, abre caminos para la interacción, la socialización entre sordos y oyentes y la difusión del lenguaje de señas más allá de las paredes de la escuela. Por lo tanto, en esta línea de comprensión, este artículo se guió por la siguiente pregunta central: ¿la implementación de la disciplina de Libra en los primeros grados de la escuela primaria I contribuiría a la formación del sujeto sordo y a la promoción efectiva de la inclusión entre las personas sordas y oyentes? Con este fin, los objetivos esbozados fueron: Entender el bilingüismo como formas de hacer que la inclusión sea efectiva, con el fin de implementar la disciplina de Libra en los primeros años, enumerar las acciones para que estas políticas se lleven a cabo, analizar cómo, teniendo su lengua materna el comienzo de su entrenamiento favorecería el proceso de identidad del sujeto sordo; Investigar las políticas públicas y la legislación educativa, como subsidios que permitirán la implementación de la disciplina de Libra en los primeros años desde la perspectiva de una escuela bilingüe y comprender cómo los miembros de la escuela conciben la implementación de la disciplina de Libra en los grados iniciales mientras promueven la inclusión de sordo Seguimos los caminos metodológicos basados en el enfoque cualitativo, inspirados en el estudio de caso, apoyados por instrumentos como visitas de campo, entrevistas semiestructuradas y observación. Los sujetos de investigación fueron estudiantes sordos, oyentes, intérpretes y también maestros que corroboraron en sus discursos la importancia de implementar la disciplina de Libras para sordos y oyentes desde los grados iniciales de primaria I, ya que, entre otras cosas, favorecerá el proceso de identidad. y comunicación.

Palavras-chave: Educação Bilíngue; Educação de Surdos; Políticas Públicas.

Keywords: Bilingual Education; Deaf Education; Public policy.

Palabras claves: Educación bilingüe; Educación para sordos; Políticas públicas.

\section{INTRODUÇÃO}

A atual conjuntura da educação especial, na perspectiva da educação inclusiva, tem fomentado a discussão sobre a temática das Políticas Públicas na Educação de Surdos, sendo o Bilinguismo o viés mais consistente. Isso se justifica diante da proibição do uso da língua de sinais, no Congresso de Milão em 1880, quando foi implantado, obrigatoriamente nas escolas, o modelo educacional oralista. Esta ação trouxe grandes prejuízos para os surdos em 
vários aspectos e estes iniciaram um período longo e exaustivo de incansável luta, na tentativa de resgate, de novamente ter como língua de instrução, a língua de sinais.

Os resquícios dessa proibição são sentidos ainda hoje, pois muitas escolas não se sentem seguras quanto ao modelo mais apropriado, na expectativa de garantir educação de qualidade para os alunos surdos. Há uma necessidade desses alunos passarem pelo processo de aquisição da língua de sinais, até mesmo para que tenham autonomia linguística, para serem inseridos e incluídos em outros espaços e, é na escola que isso também precisa acontecer.

Uma das formas de promover a efetiva inclusão é repensar sobre a língua utilizada pelos partícipes que convivem no espaço escolar, neste caso os surdos e ouvintes, analisar como ela é aprendida e veiculada. A língua é a porta de entrada para a comunicação e interação entre seus usuários, estreita as relações, promove a discussão e a troca de experiências em diversos níveis e modalidades.

Assim, nesta linha de entendimento, este artigo foi orientado pela seguinte questão central: a implementação da disciplina Libras nas séries iniciais do ensino fundamental, contribuiria na formação do sujeito surdo e na promoção efetiva de inclusão entre surdos e ouvintes? Como objetivos específicos destacamos: a. Analisar, a partir do modelo educacional bilíngue, de que maneira ter a sua língua materna no início de sua formação favoreceria no processo identitário do sujeito surdo; b. Investigar as políticas públicas e as legislações educacionais, como subsídios que possibilitarão a implementação da disciplina de Libras nos anos iniciais na perspectiva de uma escola bilíngue; c. Perceber como os integrantes das escolas concebem a implantação da disciplina de libras nas séries iniciais enquanto promoção da inclusão de surdos.

Foi adotada como caminhos metodológicos neste trabalho, a abordagem qualitativa, com inspiração no estudo de caso, alicerçada por instrumentos como visitas de campo, entrevista semiestruturada e observação. Os sujeitos da pesquisa foram alunos surdos, ouvintes, intérprete e também professores da rede pública de ensino. Seguiremos as discussões a partir de uma breve revisão das políticas públicas na educação de surdos, para que possamos compreender a contribuição dessas ações e suas fragilidades no processo de disseminação da língua de sinais, bem como o uso do bilinguismo, percebendo, mediante as falas dos colaboradores, o impacto da disciplina de Libras no dia a dia de surdos e ouvintes, dentro e fora do espaço escolar.

São muitas as indagações que rodeiam e nos instigam a repensar o currículo escolar, acreditando que essas são estratégias favoráveis na concretização, ampliação e efetivação de políticas públicas de inclusão na escola que, por sua vez se dissemina em todo um contexto sociocultural onde os sujeitos estão inseridos e, pensando nisso, é que nos propomos a fomentar aqui uma das mudanças curriculares, sendo esta a implantação de Libras nas séries iniciais, desejo este ratificado nas vozes dos nossos participantes.

\section{POLÍTICAS PÚBLICAS NA EDUCAÇÃO DE SURDOS}

A educação de surdos, na perspectiva da educação especial e da educação inclusiva, perpassou por vários modelos educacionais. Os principais 
deles foram o oralismo - os surdos eram proibidos de sinalizarem, esperavam que eles se integrassem apenas com a oralização. Era uma visão clínicoterapêutica, que consistia na prática do treinamento da fala, estes deveriam ser "ouvintizados", ou seja, se encaixarem nos padrões da normalidade; O surdo não era encarado como um sujeito na sociedade, mas com um ser com uma patologia que precisava ser consertada. Os ideais de homogeneização não se consolidaram, e os efeitos foram desapontadores. E, apesar dos esforços na pretensão de fazer o surdo um ouvinte, como afirma Lima (2015, p.47) "seus ideais fracassaram e juntos com eles a educação de surdos".

Outra tentativa foi a comunicação total - apesar de ter sido apresentado como sendo mais vantajoso que o oralismo, por fazer com que o surdo aprendesse a Língua Portuguesa sinalizada na perspectiva de uma organização alfabética direcionada ao falante, esta não favorecia o surdo, pois este continuava em segundo plano; isso, porque nessa perspectiva, também conhecida como Bimodalismo, ou português sinalizado, eram usados todos e quaisquer recursos que compreendiam viabilizar um meio de comunicação, como é descrito a seguir:

Uso de recurso espaço-visório-manuais como suportes facilitadores da comunicação, utilizando simultaneamente a língua oral, língua de sinais, a mímica, a expressão corporal e facial, a leitura labial, o desenho, a dramatização, o treino auditivo, a escrita, a datilologia, entre tantas outras formas de aprender. Sendo a língua de sinais e os diferentes recursos visuais apenas apoios que facilitam a comunicação, o ensino e a aprendizagem (LIMA, 2015, p.48. apud BOTELHO, 2010, p.123).

Nesta visão, é compreensível entender porque a Comunicação Total configurou-se um fracasso como modelo educacional da educação de surdos. Não havia uma sequência lógica de um modelo gramatical de uma língua independente da outra. E nesta miscelânea linguística não contemplava o aprendizado eficaz do aluno. Infelizmente ainda há resquícios desse modelo em algumas instituições que estão no processo inicial de construção ou de primeiras experiências com alunos surdos.

Por fim, o bilinguismo é, até então, a melhor proposta de educação surda. Consiste em dominar a língua de sinais como primeira língua, priorizando as especificidades gramaticais, linguísticas e os aspectos culturais do povo surdo e a escrita do português como segunda língua.

Em anos recentes, algumas políticas públicas foram adotadas visando garantir a inserção e permanência de alunos com necessidades específicas nos espaços educacionais, destacamos algumas dessas medidas focando a educação de surdos.

A resolução 02, de 11 setembro 2001, que institui Diretrizes Nacionais para a Educação Especial na Educação Básica, no Art. 12 define que "os sistemas de ensino, nos termos da Lei 10.098/2000 e da Lei 10.172/2001,

$\S 2$ Deve ser assegurada, no processo educativo de alunos que apresentam dificuldades de comunicação e sinalização diferenciadas dos demais educandos, a acessibilidade aos 
conteúdos curriculares, mediante a utilização de linguagens e códigos aplicáveis, como o sistema Braille e a língua de sinais, sem prejuízo do aprendizado da língua portuguesa.

Embora esta resolução traga uma abordagem sobre acessibilidade aos conteúdos e uso da língua de sinais, cabendo aqui uma interpretação, para a especificidade da surdez, ela não prioriza a língua de sinais como língua de instrução e que esta deva ser usada apenas "para" aqueles que apresentam dificuldades na comunicação e não que ela deva ser difundida na unidade escolar. Ela não abre uma brecha para que seja constituída uma proposta de ensino de Libras para surdos e para ouvintes.

No ano seguinte, mediante a Lei 10.436 de 24 de abril de 2002, a Língua de Sinais finalmente é reconhecida como meio de comunicação e expressão oriundas das comunidades surdas do Brasil. Três anos depois, o decreto 5.626, de 22 de dezembro de 2005 regulamenta esta lei, trazendo algumas especificações sobre surdez, classes e escolas bilíngues. A referida lei define que a língua de instrução do surdo brasileiro é a Libras e a modalidade escrita a Língua Portuguesa. Mas, alguns questionamentos são levantados para que se amplie ou se esclareça qual o significado real do bilinguismo no contexto da inclusão:

Mas, só aos estudantes surdos e surdas há duas línguas de instrução no processo educativo? Quando o decreto fala de bilinguismo, somente os surdos se incluem? Por que em nenhum momento aparece a Libras como segunda língua dos estudantes ouvintes? (LIMA, 2015, p.65).

É muito comum ver esses mesmos questionamentos serem feitos por alunos, professores e surdos em sala de aula e nos eventos, cuja temática é inclusão de surdos. Nesta abordagem, a difusão da língua de sinais nos espaços escolares, por meio da implantação da disciplina de Libras, tornaria possível a comunicação entre os alunos surdos e ouvintes. Muitos ouvintes participariam da comunidade surda se soubesse a língua de sinais. Alguns aprendem com o próprio surdo. Mas, e se o surdo não sabe a língua de sinais? Este também precisaria aprender. E como isso pode ser feito no ambiente escolar, para surdos e ouvintes? Reflexões como essas são necessárias e com urgência nas respostas.

Essa política pública de ensino e difusão da língua de sinais prevista pelo Decreto 5626/02 já citado, abriu caminhos de manutenção de Libras como língua, independente da forma como for adquirida, quer surdos que aprenderam com pais surdos, quer tenham aprendido na comunidade surda. Daí vem à proposta de ações afirmativas, significativas e pertinentes como a apresentada por Quadros (2017) sobre a qual comungamos: a inclusão de Libras como disciplina no currículo escolar tanto para crianças surdas como para as crianças ouvintes, filhas de pais surdos, como língua de herança, primeira língua. O desafio acerca da educação bilíngue, e a efetivação da inclusão são crescentes:

Essa inclusão vai além do ensino de Libras como segunda língua para as demais crianças ouvintes, pois diferente da 
metodologia de ensino de língua fundamentado em proposta de ensino de segunda língua, a Libras, como língua de herança, passa a ser ensinada nesses contextos específicos, com proposta de ensino de primeira língua (QUADROS, 2017. p 132).

Nesta perspectiva, a autora argumenta que a modalidade de aprendizado não teria como ponto de partida a língua portuguesa. Os ouvintes, filhos de pais surdos ou ouvintes, aprenderiam a língua de sinais na estrutura de primeira língua, de forma natural das línguas visuais-motoras.

Ainda sobre sua experiência como pesquisadora acerca do desenvolvimento da linguagem em crianças surda e com uma afirmativa chocante, a autora do livro Língua de Herança expressa: "vi que as crianças surdas estavam sendo castradas, ao não serem exposta à língua de sinais" (QUADROS, 2017, p.154). Fica evidente nas palavras da autora que não há para os sujeitos surdos direitos iguais no uso de sua língua. É uma caracterização de castração no sentido do surdo não usufruir todas as possibilidades que a língua lhe proporcionaria. A língua liberta. A falta dela causa isolamento, constrangimentos, fobia social, apatia, e outros danos sociais. No ambiente escolar é muito frequente o isolamento e a probabilidade de sofrer bullying.

Mais recentemente, os surdos foram surpreendidos de modo positivo com um novo decreto sobre a educação bilingue, sendo este o Decreto $\mathrm{n}^{\mathrm{0}}$ 9.465 de 02 de janeiro de 2019, especificamente o artigo 35, onde reza que compete à Diretoria de Políticas de Educação Bilíngue:

I - planejar, orientar e coordenar, em parceria com os sistemas de ensino voltados às pessoas surdas, com deficiência auditiva ou surdocegueira, e com as instituições representativas desse público, a implementação de políticas de educação bilíngue, que considerem a Língua de Sinais Brasileira (Libras), como primeira língua, e Língua Portuguesa Escrita, como segunda língua ;

II - fomentar a criação de Escolas Bilíngues de Surdos, em todo o território nacional, com oferta de educação integral, em todos os níveis, etapas e modalidades de ensino;

$\mathrm{V}$ - planejar e executar ações que visem ao fortalecimento dos Centros de Apoio aos surdos dentro das Escolas Bilíngues, para a formação educacional, elaboração de materiais didáticos bilíngues e interação com a família;

VII - formular e implementar políticas que favoreçam o acesso, a permanência e a aprendizagem nas instituições de ensino bilíngue, por meio da integração com setores de cultura, esporte e arte;

$X$ - promover e favorecer a realização de estudos e pesquisas referentes às experiências com e na educação bilíngue de surdos.

O Decreto especificou cada aspecto da educação bilíngue para surdos, desde a interação familiar, como elaboração de materiais didáticos e o que se acredita que será de grande contribuição, é o inciso $X$, aborda sobre a 
promoção e favorecimento da realização de estudos e pesquisas referentes às experiências com e na educação bilíngue de surdos, pois estas nos ajudaram a melhorar as ações de forma a favorecer surdos e ouvintes na apropriação da primeira e/ou segunda língua.

Outros questionamentos são abertos com esse decreto, pois os gestores municipais devem iniciar uma empreitada engenhosa para pesquisa, ementário, reformulação de currículo, qualificação de funcionário, promoção de eventos para divulgação da nova proposta de uma escola ou classe bilíngue. Investir em materiais didáticos visuais, com a metodologia da Pedagogia surda, ou pedagogia visual, ou seja, iniciar uma fase de adequação a essa proposta e, por sua vez, sabemos que não é uma ação fácil e que, muitas vezes não há o apoio necessário para isso.

Para compreender melhor o modelo educacional bilíngue, e de que maneira a exposição precoce à língua de sinais contribuiriam na formação identitária do sujeito surdo, a próxima sessão discutirá a concepção e proposições sobre o Bilinguismo.

\section{Bilinguismo e Surdez}

O ensino Bilíngue, conforme afirma Fernandes (2011, p. 32), "os surdos querem aprender na língua de sinais, ou seja, a língua de sinais é a privilegiada como língua de instrução". Ela ainda conclui que o significado disso vai além da questão puramente linguística, que se situa no campo político. Portanto, os surdos estão discutindo como querem aprender, e isso se tornou possível pelo empoderamento proporcionado pela língua. Surdos, filhos de pais surdos, que já nasceram numa geração de usuários fluentes em Libras, ficam expostos à língua de sinais logo cedo, e, por meio dela, constroem um pensamento político, defendendo a língua, a cultura, construindo uma identidade política forte e militante.

O reflexo desse empoderamento e desta construção identitária são outros surdos fortalecendo suas bases e, estes compreendem que a educação oferecida é a educação inclusiva, configurada com a presença do intérprete de Libras e, a educação inclusiva não é educação bilíngue. Principalmente nos moldes como a educação inclusiva tem sido promovida, a garantia é apenas que o sujeito surdo esteja inserido, mas não interagindo com o todo.

A inclusão escolar está articulada a movimentos sociais mais amplos, que exigem maior igualdade e mecanismos mais eqüitativos no acesso a bens e serviços ligados a sociedades democráticas que estão pautadas no mérito individual e na igualdade de oportunidades, a inclusão propõe a desigualdade de tratamento como forma de restituir uma igualdade que foi rompida por formas segregadoras de ensino especial e regular. A escola justa e desejável para todos não se sustenta unicamente no fato de os homens serem iguais e nascerem iguais (MANTOAN, 2006, p.16).

Em um ambiente bilíngue, "todos" saberiam a língua de sinais e isso abrange todo o corpo escolar: colegas, gestores, professores, funcionários, administradores. A língua de comunicação e instrução seria a Língua de sinais, 
uma pessoa não necessitaria aguardar a presença de um intérprete para comunicar-se com os funcionários da cantina, da lanchonete para fazer 0 pedido do seu lanche, nem na biblioteca para pedir o livro que desejasse, uma sugestão de leitura ou tirar alguma dúvida com o professor. Também poderia articular com seu colega de classe atividades propostas pelo professor quando necessário. Ele teria autonomia para fazer uma reclamação ou agradecimento de forma direta com o coordenador ou diretor, pois estes também saberiam a língua de sinais. A escola estaria estruturada para receber o aluno e não o aluno teria que passar por um processo sofrido para se adequar-se a escola.

É marcante a forma como a educação inclusiva para surdos tem sido consolidada em algumas escolas, principalmente do interior baiano. Inicialmente a educação de surdos era segregativa, daí pleiteou-se a inclusão para que as crianças surdas interagissem com as crianças ouvintes. Aos poucos, os educadores foram percebendo que muitos ouvintes ou a maioria deles não interagiam linguística nem socialmente com os surdos e, a integração não acontecia de forma efetiva.

A perspectiva de inclusão está sendo baseada apenas pela entrada do surdo na escola, mas não se sustenta, pois, incluir carece de ações diárias de permanência, empoderamento e promoção da equidade. Conforme Chaveiro, Barbosa (2004, s/p), a "Libras se torna uma ferramenta de empoderamento que permite ao surdo maior mobilidade e fluidez nas formações discursivas, como também fornece subsídios que ajudem na constituição de suas identidades frentes as imposições (culturais e outras) do ouvinte".

Por sua vez, acreditamos que, uma das formas de promover a efetiva inclusão é repensar sobre a língua utilizada pelos partícipes que convivem no espaço escolar, neste caso os surdos e ouvintes, como ela é aprendida, veiculada. A língua é a porta de entrada para a comunicação e interação entre seus usuários, estreita as relações, promove a discussão e troca de experiências em diversos níveis e modalidades.

O conceito distorcido de bilinguismo ainda é perceptível em muitas unidades escolares, que acreditam que esta proposta se fundamenta em ter um intérprete de Libras para intermediar a comunicação dos surdos no processo de ensino/aprendizagem. Esse equívoco é fortalecido ainda pela desinformação de alguns profissionais com relação às atribuições do intérprete de Libras, pois acham que esse profissional poderia ser mais participativo no processo de aprendizagem, por "ensinar" melhor ao surdo.

Esse conceito vai além. A escola precisa ser pensada, preparada para receber essa modalidade de ensino bilíngue. Então, o que caracteriza a educação bilíngue para crianças surdas nos anos iniciais?

O bilinguismo defende a condição do sujeito surdo visando garantir seus direitos lingüísticos e de cidadania. Os estudantes surdos tem o direito de serem educados na sua primeira língua e também o direito de aprenderem a língua portuguesa, como segunda língua, na modalidade escrita(...) o bilinguismo possibilita transformar modos de como se pratica(va) o ensino e a educação de surdos (LIMA, p. 79, 2015).

É relevante pensar a escola como um lugar, um espaço de interação social. Mas como interagir se os envolvidos não se comunicam por meio de 
uma língua em comum? À criança surda é garantido o direito de aprender a língua de sinais de modo natural. Alguns fatores não tornam isso possível, como o fato de $95 \%$ de crianças surdas nascerem em lar de pais ouvintes e esse contato com a língua de sinais acontecerem tardiamente. No entanto, quanto mais precoce ocorrer essa exposição à língua, mais autonomia a pessoa surda terá.

Propiciar à pessoa surda a exposição a uma língua o mais cedo possível, obedecendo as fases naturais de sua aquisição é fundamental ao seu desenvolvimento. Privá-la desse direito, sob qualquer alegação, é desrespeitála em sua integridade (CORREIA; FERNANDES, 2011 p. 18).

$O$ desrespeito estende-se também quando essa criança inicia a vida escolar e não encontra um ambiente acolhedor. A proposta é inclusiva, porém, a prática normalmente não condiz com o proposto. E quando a língua de sinais não é usada como língua de instrução ou quando não há a disciplina para a turma quando esta é inclusiva, o desrespeito pode ter um efeito devastador tanto na infância, quanto na adolescência e, se o fato permanecer, o prejuízo será estendido para a vida adulta.

Ainda assim, por conta das políticas existentes, as crianças surdas são matriculadas na escola regular comum, e, não havendo acessibilidade em todos os aspectos, os danos irão além da interação social,

\begin{abstract}
Entretanto, quando se opta pela inserção do aluno surdo na escola regular, essa precisa ser feita com cuidados que visem garantir sua possibilidade de acesso aos conhecimentos que estão sendo trabalhados, além do respeito por sua condição linguística e, portanto, de seu modo peculiar de ser no mundo. Isso não parece fácil de ser alcançado e, em geral, vários desses aspectos não são contemplados nas experiências inclusivas em desenvolvimento, pois a criança surda, com freqüência, não é atendida em sua condição sociolinguística especial, não são feitas alterações metodológicas que levem em conta a surdez e o currículo não é repensado, culminando em um desajuste socioeducacional (LODI; LACERDA, p.15, 2014).
\end{abstract}

Uma das formas de repensar o currículo é propor a inserção da disciplina de Libras nos anos iniciais. Essa estratégia possibilitaria aos alunos ouvintes aprenderem a língua de sinais, fomentando a acessibilidade comunicativa entre os partícipes do espaço escolar em todos os contextos e, possibilitaria ao aluno surdo a aquisição da sua língua, tornando a compreensão dos conteúdos mais significativos e contribuindo para o processo identitário desse sujeito.

E em relação a compreender se, ter a educação bilíngue com a disciplina de Libras nos anos iniciais, favoreceria no processo identitário do sujeito surdo, é possível fazer a seguinte reflexão:

Para além da questão da língua, portanto, o bilingüismo na educação de surdos representa questões políticas, sociais e culturais. (...) Assim, a educação de surdos na perspectiva bilíngue toma uma forma que transcende as questões puramente linguísticas. Esta escola está sendo definida pelos 
próprios movimentos surdos: marca fundamental da consolidação de uma educação de surdos em um país que se entende equivocadamente monolíngue (FERNANDES, p.35, 2011).

Essa mudança no fortalecimento da identidade surda, principalmente na questão cultural, é um dos artefatos da cultura surda, é a política, que consiste, conforme Strobel (2008), em diversos movimentos e lutas do povo surdo pelos seus direitos. Esses movimentos são feitos por surdos que freqüentam e participam de associações de surdos ou outros espaços de encontros surdossurdos, espaços de fortalecimentos, discussões e a língua usada, é língua de sinais. Compreende-se assim, que para a criança surda, ter acesso à língua de sinais nos anos iniciais poderá ter um reflexo em suas ações a nível social e político na posteridade.

Há em outros países, a exemplo do Paraguai, mais especificamente em Assunção, a implantação do bilinguismo para toda a população. É sabido que o país tem parte de sua população de etnia indígena, lá vivem muitos índios de origem Guarani. Como meio de valorização da cultura do país, de facilitar a comunicação entre a população e ainda o fortalecimento e empoderamento de um povo, além da língua espanhola, idioma oficial dos pais, o Guarani está sendo ensinado nas escolas e seu uso é contínuo em outros espaços sociais.

Os aprendentes estudam as línguas de forma concomitante e, como facilitador da escrita, esta é codificada a partir da oralidade, ou seja, da maneira que as palavras são pronunciadas em Guarani, são escritas nesta língua, há a "tradução" oral e escrito para o espanhol, efetivando assim o processo bilíngue. O professor não precisa de intérprete para o uso da língua materna deste grupo na escola, todos os envolvidos no processo educacional utilizam as duas línguas, fazendo escolha mediante a situação, a condição do seu interlocutor.

Situações como essas nos fazem acreditar que, é possível a implantação de Libras nas séries iniciais, o ganho desta política de afirmação não seria apenas para o surdo, mas favoreceria a comunidade ouvinte, permitindo a este a aquisição de uma nova língua e conhecimento de uma cultura, que convive com a sua e é invisibilizada por um preconceito linguístico e social.

\section{CAMINHOS METODOLÓGICOS}

O interesse nessa pesquisa surgiu a partir de um artigo proposto pelo curso, onde foram realizadas algumas visitas numa escola estadual no interior da Bahia que tem vários alunos surdos inseridos e, neste contexto, percebemos a luta incansável dos profissionais e demais envolvidos para tornar esse processo menos difícil para os surdos. Algumas das dificuldades encontradas eram surdos sem aquisição linguística, professores em processo de formação na área de educação de surdos e outras barreiras. Se o surdo não tem essa habilidade linguística tampouco haverá compreensão das atividades conteudistas apresentadas pelos professores. Caracterizando assim perdas significativas para 0 discente surdo, tornando 0 ambiente de ensino desproporcional quando comparado com o restante do público ouvinte. 
Em contrapartida, percebemos alguns ouvintes com interesse de aprender a língua de sinais, intérpretes interessados em cumprir suas atribuições e intermediar esse processo de comunicação. Mas, isso não era suficiente para abarcar um ensino qualitativo, pois não havia um tempo adicional para esses alunos aprenderem de forma mais coerente à língua de sinais, de modo mais natural e com liberdade para tirarem as dúvidas e compreenderem questões culturais e identitárias dos surdos. Além dessas questões que envolvem os ouvintes, os surdos precisavam se desdobrar numa jornada exaustiva para aprender a língua de sinais, a Língua portuguesa na modalidade escrita, e isso acontece em turno oposto, e ainda, no caso de muitos, em outro espaço escolar, nas salas que oferecem o Atendimento Educacional Especializado - AEE.

Esse quadro mostra um grande distanciamento da proposta eficaz da educação bilíngue para surdos. $\mathrm{Na}$ definição apresentada, podemos compreender que:

Se a língua de sinais é uma língua natural adquirida de forma espontânea pela pessoa surda em contato com pessoas que usam essa língua e se a língua oral é adquirida de forma sistematizada, então as pessoas surdas têm o direito de ser ensinadas na língua de sinais. A proposta bilingue busca captar esse direito. (QUADROS, 2008).

Refletindo desta forma, percebemos a necessidade dos alunos surdos adquirirem, de forma espontânea, a língua de sinais e, por meio desta, ter acesso às informações e conteúdos estabelecidos pela matriz curricular da escola.

Assim, precisávamos pensar em espaços escolares que, comungassem ou não, a revisão do seu currículo com o acréscimo de Libras como disciplina. As escolas pesquisadas já discutiam de formas diversas sobre Educação Inclusiva e Surdez, em virtude de terem em seu quadro alunos surdos. Todas elas são públicas e concentram-se no interior baiano.

\section{Método e participantes envolvidos}

O pesquisador precisa compreender a sua função mediante o universo a ser pesquisado, para que não venha, mediante seus valores pessoais, promover uma visão equivocada, preconceituosa e estereotipada dos dados coletados, comprometendo o cunho científico do trabalho. É necessária uma reflexão epistemológica sobre as teorias do conhecimento que se deseja trabalhar, bem como uma análise cuidadosa do universo pesquisado, para que se proceda ao recorte teórico e metodológico que mais se adeque ao trabalho.

O caminho metodológico deve ser apropriado ao tipo de estudo que se deseja realizar, sendo determinado pela natureza do problema e seu nível de aprofundamento. Neste caso, a pesquisa qualitativa, em sua vertente, pressupõe direcionar o interesse do pesquisador "para compreender as ordens socioculturais em organização, constituídas por sujeitos intersubjetivamente edificados e edificantes, em meio a uma bacia semântica culturalmente mediada" (MACEDO, 2006, p. 09, grifo do autor). 
Para tratar desta temática adotamos como caminhos metodológicos a abordagem qualitativa, com inspiração no estudo de caso, alicerçada por alguns dispositivos a serem usados na análise de dados como, visitas de campo para discussão e estudo da proposta, entrevista semiestruturada e observação. Segundo Yin (2001, p.32): "o estudo de caso é uma investigação empírica de um fenômeno contemporâneo dentro de um contexto da vida real, sendo que os limites entre o fenômeno e o contexto não estão claramente definidos". Pretendemos por meios desses dispositivos, levantar informações necessárias para alinhá-las à pesquisa teórica e assim apontarmos caminhos para os direitos já adquiridos pelos surdos de ter o ensino de língua sinais nos anos iniciais do fundamental I, contemplando o ensino bilíngue, de forma a estender esse direito aos ouvintes.

Como propõe o método, nesta pesquisa propomos olhar a realidade social, uma realidade escolar que pressupõe construção de identidade de sujeitos invisibilizadas. A participação de cada um nesta proposta é de extrema importância, os dados coletados poderão ajudar na efetiva implementação da disciplina nas escolas, por exemplo, os gestores que demonstrarem interesse em implantar a disciplina na escola, encontrarão, além de um direcionamento legal para pautar as solicitações, justificando o aspecto linguístico, social, cultural e identitário dos surdos, o respaldo desta pesquisa, sinalizando a possibilidade e o interesse da comunidade escolar, em favorecer a efetiva comunicação entre surdos e ouvintes, o empoderamento surdo, na construção de sua identidade $e$, o respeito às diferenças numa ação de equidade.

\section{RESULTADOS E DISCUSSÃO}

Para responder aos objetivos adjacentes já elencados e a questão central deste artigo: - Como a implementação da disciplina Libras nas séries iniciais do ensino fundamental, contribuiria na formação do sujeito surdo e na promoção efetiva de inclusão entre surdos e ouvintes? Participamos de alguns encontros de estudo, realizando a partir daí entrevistas, que dialogamos com alguns autores, com a finalidade de que haja a percepção da necessidade da implantação da disciplina nos anos iniciais do aluno surdo.

A princípio, tomaríamos como locus da pesquisa uma escola, mas como percebemos que esse é uma proposição mais abrangente, o grupo escolheu entrevistar colaboradores de três cidades baianas. Foram entrevistados intérpretes, alunos surdos, ouvintes, professores de escolas públicas, sendo aqui destacado apenas alguns registros. Foi acordado que a identidade dos colaboradores seria preservada, e as entrevistas escolhidas para socialização serão denominados neste artigo como Surdo 1 e Surdo 2, Ouvinte, Intérprete, Professor 1, sendo descrito um breve perfil e a contribuição desses partícipes.

\begin{tabular}{|l|l|l|ll|}
\hline COLABORADORES & \multicolumn{1}{|c|}{ IDADE } & \multicolumn{1}{c|}{ FUNÇÃO } & \multicolumn{2}{c|}{ ESCOLARIDADE } \\
\hline SURDO 1 & Entre 15 e 18 anos & Estudante & $\begin{array}{l}2^{0}-\text { Técnico em } \\
\text { Agroindústria }\end{array}$ \\
\hline SURDO 2 & Entre 20 e 30 anos & Estudante & Cursando Psicologia \\
\hline OUVINTE 1 & Entre 8 e 15 anos & Estudante & Ensino Fundamental I \\
\hline INTÉRPRETE 1 & Entre 20 e 30 anos & Intérprete & Licenciada em Letras \\
\hline PROFESSOR 1 & Entre 30 e 40 anos & Regente & Mestre em Diversidade \\
\hline
\end{tabular}

Fonte: Autores, 2019 
Surdo 1 é estudante do $2^{\circ}$ ano do Curso Técnico em Agroindústria integrado ao Ensino Médio, aprendeu a língua de sinais com uma professora na escola fundamental, teve a entrevista mediada por uma Intérprete de Libras. A Intérprete é Graduanda em Letras/Libras, pós graduanda em Libras, com proficiência no uso e no ensino de Libras e Proficiência na Tradução e Interpretação em Libras.

Ao serem questionadas sobre o que acham da implementação da disciplina de Libras nos anos iniciais como proposta bilíngue, tanto para alunos surdos como para alunos ouvintes, os participantes responderam:

A falta do ensino da Libras nos anos iniciais me deixou triste, porque não tinha ninguém para me ajudar e ninguém me entendia, eu usava gestos para pedir, dizer que tinha fome, me sentia desprezada. É importante a escola ser bilíngue porque quando a aula é feita para ouvintes tem apenas poucos ou só um surdo não compreende nada e muitas vezes eu até saia da sala por não estar entendendo. (SURDA 1, 2019).

Acho que é de suma importância, a disciplina de Libras deveria ser obrigatória no currículo desde os primeiros anos iniciais, pois a partir da aquisição da Libras os surdos passam a ter acesso ao conhecimento de mundo. E se a disciplina for implementada no currículo os alunos ouvintes terão acesso à Líbras e facilitará a aquisição da mesma. Além de ser um meio eficaz de difundir a cultura surda. (INTÉRPRETE 1, 2019).

A educação é um direito de todos, deve ser de qualidade, priorizando a língua de sinais para as crianças surdas, a partir, como propomos, das séries iniciais, sendo esta a língua de instrução, formando cidadãos fluentes, independentes e capazes de construir uma experiência linguística prazerosa, comum das línguas naturais. No entanto, sem ações efetivas como formação de professores, materiais visuais, um currículo pensado em contemplar o estudante surdo, tudo será apenas utopia. A proposta é quebrar essa conceituação do "não podemos fazer nada". É possível sim e, essa afirmativa parte de experiências exitosas que alavancaram a educação de surdos no Brasil.

A Surda 2 é Técnica em Agrotecnologia, Graduanda em Psicologia, aprendeu a língua de sinais em cursos e também por meio de livros, e quando questionada sobre a mesma temática fez a seguinte consideração.

Acho que é muito importante que as crianças aprendam Libras e o português para se comunicar, estudar para ajudar as pessoas, o futuro pode ser melhor. Poderão entender tudo perfeitamente, e ter uma boa comunicação. (SURDA 2, 2019).

Mais uma vez percebemos o destaque dado a importância da Libras na comunicação entre os sujeitos sejam eles ouvintes ou surdos e o quanto o contato e uso da sua língua materna lhe possibilita ir além do que é, melhor, é compreender "tudo perfeitamente", possibilidade de liberdade linguística, a liberdade para experimentar a cultura surda, que, conforme Strobel (2008), "é o 
jeito de o sujeito surdo entender o mundo e de modificá-lo a fim de se torná-lo acessível e habitável".

Ao serem questionado como o ensino de Libras nos anos iniciais contribuiria na formação do sujeito surdo a nível linguístico e identitário, tiveram o seguinte posicionamento:

A falta da Libras me fazia não querer estudar, porque eu ia para escola mas não entendia nada, eu não conseguia aprender. Eu não tinha um sinal, não entendia o que é ser surda, somente depois que os professores começaram a me ensinar Libras aprendi e conheci outros surdos. É preciso ensinar Libras desde criança. (SURDA 1, 2019).

A partir da Aquisição da Libras o sujeito surdo passa a ter acesso ao conhecimento de mundo. Todo conhecimento será melhor absorvido pelos surdos se os mesmos tiverem acesso à Libras. $O$ acesso tardio à língua pode atrasar 0 desenvolvimento cognitivo e linguístico dos mesmos e além disso pode levá-los a não conhecerem e/ou reconhecerem sua própria cultura e assim pode interferir na sua identidade como sujeito surdo, deixando-os a parte por não se sentirem parte contra nem da cultura dos ouvintes nem da cultura dos surdos fazendo assim dos mesmos pessoas sem identidades definidas. (INTÉRPRETE, 2019)

Neste contexto é perceptível tanto na expressão da surda quanto da intérprete quanto que se faz necessário ter Libras nos anos iniciais. Primeiro o impacto na identidade do surdo. Nem sempre haverá o encontro surdo-surdo, mas poderia haver o encontro surdo-libras. E poderia ser com os ouvintes, haveria estímulo, haveria comunicação entre os colegas ouvintes, até que fosse possível o contato surdo-surdo. E o outro impacto é o linguístico, que interfere no cognitivo, no aprendizado, que por sua vez cria barreiras entre os colegas, constrangimentos, e quando chega o intérprete, demora de acontecer a adaptação em muitos casos.

Outra entrevistada possui 09 anos de idade, estuda no $4^{\circ}$ ano do ensino fundamental I, na Cidade de Camaçari, o pai foi o mediador da entrevista, e quando perguntado sobre se ela sabia o que é Libras, a resposta foi a que segue:

Sim, é a Língua Brasileira de Sinais. Eu Sei porque fui algumas vezes para as aulas de Libras na Faculdade com o meu pai, com a professora (...) onde aprendi alguns sinais e em casa ele me ensinou algumas coisas em Libras também. $E$ foi muito divertido. (OUVINTE, 2019).

Ao ser questionada se seria interessante a possibilidade de ter a disciplina na escola também para os ouvintes ela opina:

Sim, porque se entrasse um aluno surdo os alunos já saberiam. $\mathrm{E}$ também se você encontrasse um surdo na rua você já saberia falar com ele, pois na escola ensinou. Nunca estudei 
com um colega surdo, mas os pais de meu colega da escola são surdos. Meu colega não é surdo, mas ele fala com os pais dele em Libras, mas ele faz bem rápido. Também ensinei a minha amiga de escola alguns sinais. (...) fiz alguns diálogos com meu papai. (OUVINTE, 2019)

$\mathrm{Na}$ explicação desta criança, já notamos a maturidade em perceber a condição de favorecimento que a disciplina Libras daria na escola a surdos e ouvintes, as relações, o processo interacional foi pontuado para além dos muros da própria escola, enquanto condição humana, na necessidade da comunicação entre os seres. Na resposta anterior, ela demonstra a satisfação que teve ao conseguir desenvolver alguns sinais em casa, imagine estes em uso frequente em qualquer ambiente.

Encontramos aqui uma situação atípica, a entrevistada tem um colega "CODA - sigla que define filhos ouvintes de pais surdos, a partir da criação da organização internacional Children of Deaf Adults" (QUADROS, 2017). Isso é interessante porque a mesma expressa que "meu colega não é surdo, mas ele fala com os pais em Libras". Para ela foi significativo os momentos que ela participou das aulas de libras com o pai, a ponto de se sentir responsável em ensinar a outra coleguinha o que estava aprendendo, e também de conversar com o colega sobre a surdez dos pais, a ponto de perceber "a fluência" a rapidez da sinalização dele. Esse foi um dos resultados mais significativos encontrados, pois, é um parâmetro do alcance e da proporção que tomaria um currículo pensado para que todos aprendessem libras nos anos iniciais, e essas crianças ouvintes, filhos de pais surdos, tivesses orgulho de ter essa língua de herança. Essa experiência mostra que:

Alguns filhos de pais surdos conversam com seus pais sem usar a língua de sinais.(...) A experiência desses pais com as línguas também parece impactar a forma como seus filhos estabelecem a relação com os pais. Os codas que são considerados bilíngües bimodais equilibrados em geral tiveram pais surdos que são extremamente positivos em relação à língua de sinais e sentiam-se à vontade em conversar com seus filhos em língua de sinais. (QUADROS, p. 67, 2017)

As contribuições do uso de libras nos anos iniciais também teriam efeito de desconstrução do estigma de inferiorização da língua e do surdo. Haveria valorização e por sua vez, os filhos de pais surdos sentiriam que poderiam conversar livremente com seus pais em Libras em qualquer ambiente sem sentimento de serem ridicularizados. O exemplo citado acima mostra a aproximação, encanto e admiração por ver o colega "fazer os sinais rápidos". Ou seja, é de relevância social.

Outro sujeito de pesquisa foi é professora, e explica como foi sua experiência e contato com surdo, principalmente para colaborar com a questão da pesquisa sobre se concorda com a implementação da disciplina de libras nos anos iniciais.

Sim, o primeiro contato se deu no ensino médio, oportunidade em que tive um colega surdo. Havia uma intérprete para este colega e a direção do colégio fez um acordo com professores 
para que tivéssemos duas horas semanais de aula de libras como forma de fortalecer o vínculo e colaboração com este colega e demais surdos do colégio. $E$ conclui. Acredito que essa medida potencializa a aquisição da segunda língua para estes dois grupos de alunos, além de acreditar na facilidade de assimilação das línguas na fase da infância. (PROFESSORA 1, 2019).

Lembro que em uma das minhas aulas apareceu um garotinho de uns 11 anos surdo na porta da minha sala, era parente de um dos meus alunos de 7 ano, quando o meu aluno informou que ele era surdo, eu prontamente fia um sinal de "Oi" conforme aprendido na universidade... ate hoje guardo a cena dele vindo ao meu encontro correndo para conversar comigo. Quase chorei. Desejaria ter aprendido mais. (PROFESSORA 2, 2019).

Com certeza foi uma experiência emocionante para PROFESSORA 2, porém, teria sido uma conversa totalmente mais significativa se ela soubesse a língua de sinais desde a infância, teria outros sentidos, tanto para ela quanto para a criança. Se ela já se sentiu acolhida com um "oi", ela se sentiria totalmente em "casa" linguisticamente falando, se, todos naquele espaço soubessem a língua de sinais.

A expectativa do uso de Libras é que alcance relevância sócioeducacional, ao passo que propõe repensar espaços escolares inclusivos, integrados e os sujeitos, alunos aprendentes, surdos e/ou ouvintes, tenham a oportunidade de aprender uma língua, a língua de sinais, pois esta é de modalidade visual-motora, com estrutura gramatical própria, e de acordo com a Lei 10.436, de 24 de abril de 2002, constitui um sistema linguístico de transmissão de ideias e fatos, oriundos de comunidades de pessoas surdas do Brasil.

Docentes e discente percebem a importância da disciplina no processo de aprendizado do surdo e na oportunidade que este, assim como os ouvintes terá com o bilinguismo. Sabemos que não seria, a princípio, nada fácil, a carência de professores especializados, um estudo mais consistente sobre a temática, o embasamento com a pedagogia surda como suporte para mediação deste novo conhecimento, um aprendizado para surdos e ouvintes, professores e alunos, gestores e pessoal de apoio, um envolvimento total da escola.

Até então, o que percebermos é uma discrepância entre esta escola ideal e a escola real. Em relação à educação de surdos as inquietações são constantes, principalmente entre o quer fazer e como encontrar subsídios para a efetivação das ações que contemplem o ensino apropriado. Acreditamos que assim como os nossos colaboradores, a implantação da disciplina nas séries iniciais do ensino fundamental favoreceria para uma sociedade mais inclusiva em todos os âmbitos.

\section{REFLEXÕES E CONSIDERAÇÕES FINAIS}

Ainda hoje, temos um índice elevado de surdos adultos com déficit linguístico, com a implantação da disciplina Libras nas séries iniciais teríamos a 
oportunidade de contribuir com a construção linguística de outros sujeitos, ajudando-os a tornarem-se surdos adultos fluentes em língua de sinais, com menos dificuldades na compreensão dos conteúdos e numa caminhada mais consciente de sua identidade linguística e cultural.

Nesse sentido, os surdos não seriam como que castrados linguisticamente e socialmente. Não passariam por constrangimentos desnecessários, teriam uma vida desde a tenra infância com a acesso à informação, à comunicação, à interação familiar, escolar, interagindo neste espaço com todos, pois se formaria como sujeito com identidade e cultura surda a partir da aquisição da língua de sinais, e tudo isso possibilitado com a inserção da disciplinas nos primeiros anos.

Neste processo, o ganho não seria apenas para os surdos, os ouvintes, que são a grande maioria da população, teria por sua vez garantida uma outra língua, não sendo esta estrangeira e, que lhe possibilitaria uma comunicação real e satisfatória com os surdos, dando espaço ao encontro com uma nova cultura e a um processo menos doloroso de construção identitária e empoderamento do sujeito.

Foi possível perceber como os integrantes das escolas concebem a implantação da disciplina de libras nas séries iniciais enquanto promoção da inclusão de surdos. Há interesse por parte de crianças ouvintes em aprender a língua de sinais a fins de comunicação, de relações integrativas, de participar dos interesses em comuns, pertinentes das interações sociais. Isso faz parte da comunidade escolar. Se esse direito é proporcionado aos alunos surdos e ouvintes, então está oferecendo também mais ferramentas para a promoção de melhores cidadãos, menos preconceituosos e mais participativos na sociedade.

Não podemos deixar de levar em consideração que a proposta da educação bilingue é recente, comparada a outros modelos educacionais convencionais, e que, apesar de legalmente, haver decretos que dão margens para a implementação da disciplina de Libras nos anos iniciais, encontra-se algumas fragilidades nas definições que garanta ou que paute a obrigatoriedade desta ação nas escolas.

Ainda que os participantes desta pesquisa corroborem com a necessidade desta implantação, é preciso que se aponte, por exemplo, os responsáveis pela observância e acompanhamento desse currículo: Quais conteúdos programáticos deveriam ser garantidos em determinados períodos dos anos iniciais? Abordaria questões sócio-culturais? Identitárias?

Nesta perspectiva, percebemos a carência de novas políticas públicas de fortalecimento para efetivação do bilinguismo, fornecendo subsídios irrefutáveis para que as instituições de educação possam tomar um posicionamento com referências de currículo, avaliação e outros, tornando-se atuantes, reflexivos, objetivando a ressignificação dos encaminhamentos dados para tornar esta disciplina real e possível de ser ensinada, mediada, construída por surdos e ouvintes.

\section{REFERÊNCIAS}

ALMEIDA, Wolney. A; Educação de Surdos: formação, estratégias e prática docente. Ilhéus, BA: Editus, 2015. 
BRASIL. Resolução CNE/CEB no 2, de 11 de novembro de 2001 - Institui Diretrizes Nacionais para a educação Especial na Educação Básica. Disponível em: < http://portal.mec. gov.br/cne/arquivos/pdf/CEB0201.pdf>. Acesso em: 10 jul. 2019.

BRASIL. Lei no 10.436, de 24 de abril de 2002. Dispõe sobre a Língua Brasileira de Sinais - Libras e dá outras providências. Disponível em: http://www.planalto.gov.br/ccivil_03/leis/ 2002/l10436.htm. Acesso: 15 de jul. 2019.

CARVALHO, R. E. Educação inclusiva: com os pingos nos "is". 4. ed. Porto Alegre: Meditação, 2006.

CHAVEIRO, N.; BARBOSA, M. A. A surdez o surdo e seu discurso. Revista Eletrônica de Enfermagem, Goiânia, v. 06, n. 02, p.166-171, 2004.

FERNANDES, Eulália; QUADROS, R. M (Orgs.): Surdez e Bilinguismo. Porto Alegre: Mediação. 2010.

FORMOZO, Daniele de Paula. Currículo e educação de surdos. Dissertação (Mestrado em Educação), Universidade Federal de Pelotas, 2008.

LACERDA, Cristina Broglia Feitosa de; SANTOS, Lara Ferreira dos (Orgs.). Tenho um aluno surdo, e agora? Introdução à Libras e educação de surdos. São Carlos: Edufscar, 2013

LIMA, Camila Machado; Educação de Surdos: Desafios para a prática e formação de professores. Rio de Janeiro: Wak Editora, 2015.

MACEDO, Roberto Sidnei. Etnopesquisa crítica, etnopesquisa-formação. Brasília: Líber Livro Editora, 2006.

MANTOAN, Maria Teresa Egler, Rosangela Gavioli Pietro; Valeria Amorim Arantes, Inclusão Escolar: pontos e contrapontos. São Paulo: Summus, 2006. p.103.

QUADROS, Ronice M; KARNOPP, Lodenir B. Língua de Sinais Brasileira: estudos linguísticos. Porto Alegre: Artmed, 2004.

QUADROS, Ronice Muller de. (Org.). Estudos Surdos III. Petrópolis, RJ: Arara Azul, 2008.

QUADROS, Ronice Müller de. Educação de Surdos: A aquisição da linguagem. Porto Alegre: Artmed, 1997.

QUADROS, Ronice Muller de. Língua de Herança: Língua Brasileira de Sinais. Porto Alegre: Penso, 2017.

STROBEL Karin. As imagens do outro sobre a cultura surda. Florianópolis: UFSC, 2008. 